\title{
REPRESENTATION OF CULTURAL IDENTITY IN LIMAS HOUSE PALEMBANG
}

\author{
Dadang Hikmah Purnama ${ }^{1 *}$, Mulyanto ${ }^{2}$, Yulasteriyani ${ }^{3}$ \\ ${ }^{1,2,3}$ Department of Sociology, Universitas Sriwijaya, Palembang, INDONESIA \\ *Corresponding author; Email: dadanghikmahpurnama@unsri.ac.id
}

\begin{abstract}
This study analyzes the limas house as reflect of Palembang cultural identity, which is interpreted as the identity of "as to becoming". The change in the limas house as a cultural marker is adaptive and dynamic following changes in cultural identity, mainly a family structure, kinship relationship, gender, and marital status. This research uses a qualitative method with the structuralism and phenomenological approach. The informant criteria determined purposively. The data was collected using observation, in-depth interviews, and documentation. The study uses structural analysis to find the structure of form and the layout of the limas house. The analysis of cultural studies is carried out to provide context for the dynamics of changes in cultural identity that affect changes in the limas house. The results showed the structure of the limas house reflects the organizing the layout of the house according to family structure, kinship relationship, gender, and marital status as the cultural identity Palembang. The cultural identity is dynamic through the processes of production and reproduction, thus influencing changes in the limas house. The dynamics of change show the limas house can accommodate social continuity. Limas house is an arena that shows cultural identity through building changes that are adaptive to the social processes. Limas house needs to be protected, maintained, and developed through reinterpretation and revitalization in line with the cultural dynamics of the society.
\end{abstract}

Keywords: Limas house; representation; production; reproduction; cultural identity.

\section{INTRODUCTION}

One of the buildings with vernacular architecture in Indonesia is the limas house of Palembang in South Sumatra Province. This house has existed since the time of the Palembang Darussalam Sultanate (1455 1851) and is the residence of a noble family with the titles prince, Raden, and Masagus. Currently, the limas houses are mostly owned by descendants of noble families through the inheritance process, some of which have even been traded to other people.

The location of the limas house faces the river and extends along the river bank or over the river body in a row, thus forming linear settlement patterns, either from the right or the left of the river. This settlement pattern can also be clustered, especially houses built-in dry river deltas. This condition is inseparable from the geographical location of Palembang, which consists of rivers and mostly consists of wetlands or swamps so that it is not far from the river.

The limas house has a split pyramid roof with a rectangular building form and is located above the height of the house 1.5 - 2 meters above ground level. The layout of the limas house or house body consists of the front (luan), the middle (tenga), and the back of the house (buri). The three body parts of the limas house have different floor heights (bengkilas). The height limit between these bengkilas is a kekijing with a thickness of $5 \mathrm{~cm}$.
The architectural feature of the limas house is the result of adaptation between the natural environment and the culture of the community that meets the comfort aspect (Siswanto et al., 2011). Limas house is built according to the values, norms, and cultural rules of the community. Culture is the main factor in the formation of architectural space (Askarizad, 2018; Gulati et al., 2019), which is closely related to the structural, historical, political, economic, and social aspects of society, which are built by, from, and for the community (Sheida Ettehad, Amir Reza Karimi Azeri, 2014).

Limas house has a philosophy based on the culture of its people related to the essential values contained in the house, which contains cultural knowledge passed down from one generation to the next so that the house can reflect cultural identity (Aziz et al., 2019; Bedelean, 2012). Bourdieu (1977: 94) states that the house to a 'book' that children can read and study in understanding world views. LeviStrauss (1973) states that the house can reunite conflicting principles, such as descent and no descent, matrilineal and patrilineal kinship systems, or marriage with close and distant relatives.

Currently, Limas house has undergone many changes that cause it is no longer like the original shows that there has been a change in the form and function of the house (Taal, 2008). There have been changes in residential elements, including houses on stilts, including limas houses, both in the form of top- 
down, horizontal, and adjustment. This change cannot be separated from the process of meaning by the community, along with the socio-cultural processes that occur. The dynamics of cultural identity then affect changes in the form and layout of the house (Bambang et al., 2016).

This article analyzes changes in the form and organization of the limas house layout as a manifestation of the dynamic process of Palembang's cultural identity. Cultural identity is not a kind of permanent essence rooted in the past. Cultural identity "goes through constant change" throughout history as it "constantly plays out in history, culture and power. Cultural identity "is not an essence, but a placement" (Hall, 1996). Cultural Identity is defined as identity "as becoming". The form and layout of the limas house act as a 'cultural marker' that describes cultural identity "as becoming".

\section{METHODOLOGY}

This study uses a qualitative-verification research design with structuralism and phenomenological approach, which focuses on the form and layout of the limas house as a product of the activities of the people's minds. The technique of determining the informants was done by purposive sampling. Data were collected by observation, in-depth interviews, and documentation.

Data analysis uses structural analysis techniques and cultural studies. Researchers used structural techniques to analyze the cultural structure as reflected in the form and layout of the limas house. Analysis of cultural studies is carried out to provide a context for the dynamics of cultural identity changes that impact changes in the limas house.

Researchers analyzed the structure of the form and the layout of the limas house belonging to Pangeran Syarif Abdurachman Alhabsi. The limas house is a typical pattern of the limas house that has not undergone many changes to represent the general pattern of a Palembang limas house. Researchers also analyzed the changes in the limas house building by taking examples of cases that other researchers have studied.

\section{RESULT AND DISCUSSION}

\section{Limas House of Palembang}

The basic form of the Palembang limas house consists of three parts, namely the top (head), middle (body), and bottom (legs) (Budiyuwono, 2016). The head is in the form of a split pyramid-form roof with a slope of $45^{\circ}-60^{\circ}$, while the kitchen roof (pawon) is $10^{0}-17^{0}$. The body part of the house is the room where the occupants of the house carry out their daily activities in the house. The legs of the house are wooden poles to support the body of the house. These poles are positioned symmetrically and go into the ground. The stairs of the house are on the left and right of the house. This wooden ladder is called the kiai-kemulan.

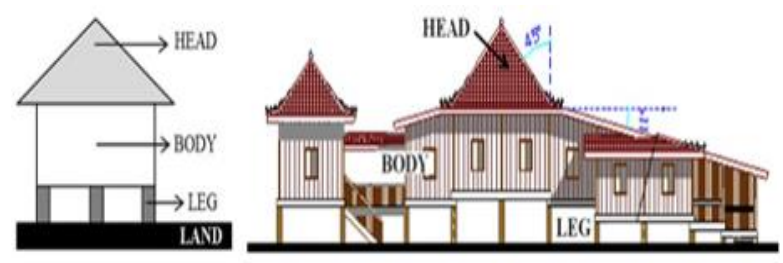

Fig. 1. Head, body, and leg of limas house (Source: Budiwiyono 2016)

The first room of the limas house after climbing the stairs is the paggar tenggalung. This space is the front porch which is bordered by an open fence (paggar tenggalung). This room has the lowest floor than the other floors. Anyone can enter this room, because this room is public. This paggar tenggalung room is a veranda and is located one level below the bengkilas bawa. In this section, there is a jogan or guard room. This room is exclusively for men, while women are prohibited from being in this jogan. Every day this room serves as a bedroom for boys (bujang). The paggar tenggalung and bengkilas bawa rooms are the luan or front of the house.

The jeroo or tenga whose floor is higher than the bengkilas bawa. Jeroo consists of bengkilas pucuk and gegajah room. The two rooms are bordered by the lawang kiyam, which is only opened when needed, such as during traditional ceremonies. The bengkilas pucuk has a lower floor than the gegajah (pedalon), which is the highest floor. This gegajah is the main room of the house under the main roof of the limas house. This room functions as a place for traditional ceremonies performed by women. Men are not allowed in this room when traditional ceremonies are being held.

The gegajah floor is further divided into three rooms, namely the amben tetuo (place for the elders), the pangkeng penganten (the bridal bedroom), and the pangkeng keluargo (the family bedroom). Amben tetuo is the floor right between the pangkeng penganten and the pangkeng keluargo. The amben tetuo has no walls, so it is open. The pangkeng penganten is on the left there is amben tetuo, while on the right is pangkeng keluargo. The pangkeng penganten functions as the place for the newlyweds' 
room, while the pangkeng keluargo or the family room of the house owner. The location of the pangkeng kepuntren is on the side of pangkeng penganten, while the pangkeng keputran is on the side of the pangkeng keluargo. Pangkeng kepuntren is a special room for girls, while the keputran is for boys.

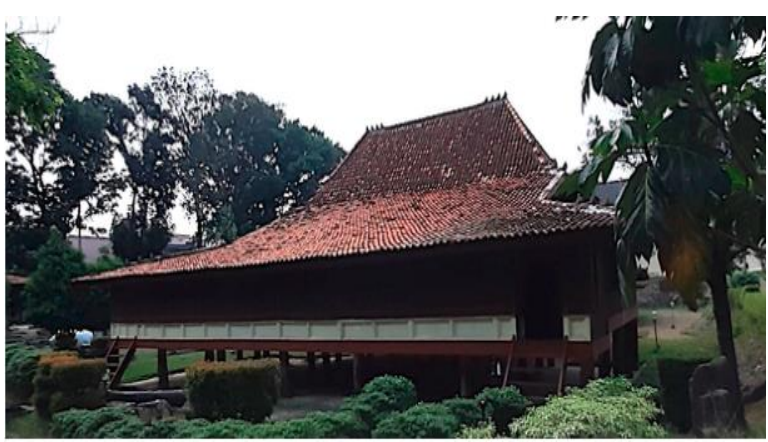

Fig. 2. Front View of Limas House

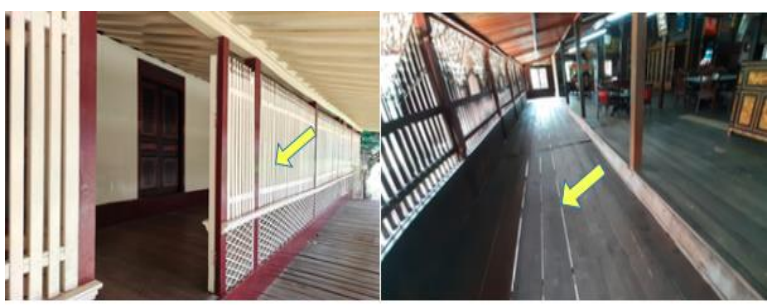

Fig. 3. Pagar Tenggulung (left) and Ruang Paggar Tenggalung (right)

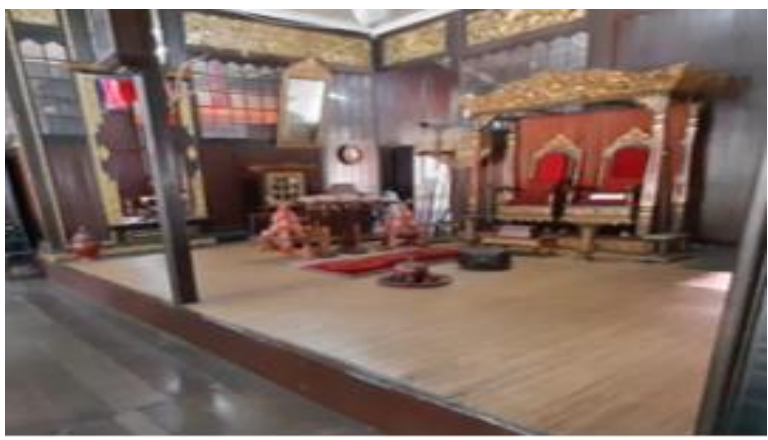

Fig. 4. Gegajah room

The back of the limas house is the buri, which functions as a pawon (kitchen). This kitchen is no longer under the main pyramid roof but has its own roof. A kitchen is a place where the food production process takes place and is sacred. Men shouldn't be in this room. There is also a nyai's (grandmother's) bedroom. The kitchen as a women's area is also associated with women as a symbol of fertility that gives life to humanity.

The legs of the limas house are wooden poles to support the body of the house. These poles are positioned symmetrically and burrow into the ground. The limas house is a house on stilts with a pole height of $1.5-2$ meters, requiring steps to enter the house. These stairs are on the left and right of the house.

The structure of this limas house forms the same pattern, which is divided into three parts of the house, both horizontally (layout) and vertically (section). The layout consists are the head, body, and leg, while the section consist is the luan (front), jeroo/tenga (central/middle), and buri (back). Two parts of the house are in opposition to each other, while the other part is united into two opposing parts to become a unity that reflects harmony.

\section{Limas House as Representation of Palembang's Cultural Identity}

According to Purnama (2000), the limas house structure shows two axes that connect the binary opposition between the paggar tenggalung (PT) pawon (PW) spaces with the pangkeng penganten (PP) - pangkeng/amben keluargo (AK) axis. The other two shafts are the axis between the jogan room (JG1) - the keputran (KPA) and the jogan room axis (JG2) - the keputren (KPE). These four axes meet at the same common ground as the centre of balance, namely amben tetuo room, thus forming a relationship structure based on social categories, namely the five classification system, which consists of four axes that are in binary opposition to each other and one point which is the centre of balance of the four axes, as shown in the following picture.

The five classification structure is symbolic, meaning that something can explain something else. The organizational structure of the layout of the limas house can explain the cultural identity of Palembang by identifying the value system and rules regarding the use of the limas house by the community. The use of spaces in the limas house is related to the social categories of whether or not the house occupants may occupy certain parts of the house according to the culture of the Palembang society. The importance of social categories in the use of space in the house is also found in the studies, which describe the relationship between the use of space in the house and the order of social relations based on social categories (Cunningham, 1964; Ng, 2006) and Purnama (2008).

The paggar tenggalung - pawon space is the first axis of the limas house classification system. The axis connects the luan which is the male territory with the buri which is the woman territory. The paggar tenggalung room is a place to receive guests who have no kinship, so it is public, while the pawon is a room that only applies to house women. Other people are not allowed into the buri, so it is private. This axis shows two rooms that have characteristics based on gender classification (Purnama, 2000). 


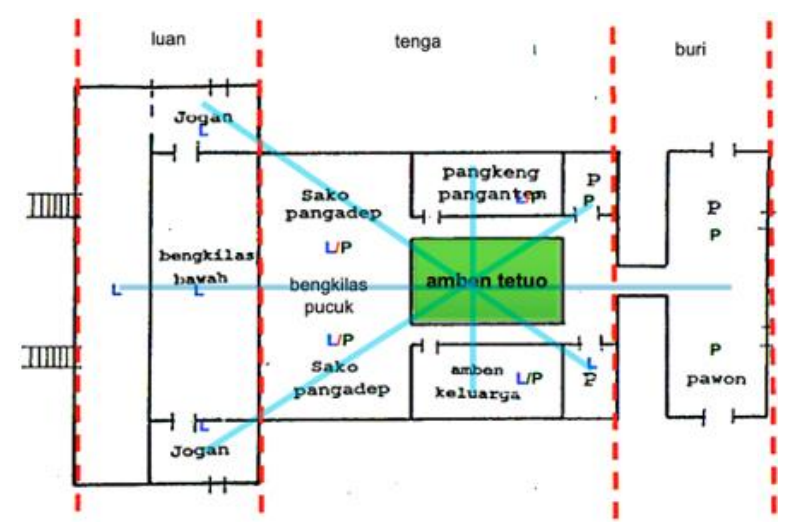

Fig. 5. Use of space according to social categories

The second axis is the pangkeng penganten amben keluargo which connects the room used by the newly married couple with the parent's room from children newly married. The axis connects two rooms that have different characteristics according to family relationship and marital status. The third axis is jogan 1 - keputran, which relates to the function of the room for boys. The jogan 1 is for boys who are growing up (akil balig), while keputran is for boys. The axis shows the use of two rooms based on the level of family relationship status. The last axis is the jogan axis 2 - keputren. The axis relates to the function of the room according to family relationship status and gender. Similar to the function of jogan 1, the jogan 2 is for boys who are akil balig, while the kepuntren is a room used for girls. These two rooms form a axis based on gender categories and family relationship status.

The four axes are centred in the amben tetuo room, thus forming a five classification system. Amben tetuo has characteristics that unite the functions of the four axes as the centre of harmony and balance, thus forming a relationship structure based on the five classification system. According to Levi-Strauss (1973), the structure appears unconsciously, which is obtained through binary oppositions and forms a system of relationships between one element and another. However, the limas house architecture building shows a structure in the form of a symbolic classification system is dynamic. The changes that occur in the form and layout of the house implicitly show changes in interpreting the concept of a limas house. This is actually as stated by Ellen (1986), who view the structure of the house architecture is not 'static'. The house represents not only one fixed order, not only an expression of order but also the expressed order must be implemented in different ways by different people in different conditions so that the meaning of the house can be carried out. There are changes.
The layout of the limas house can also be distinguished based on the category of the occupants marital status. Keputren is a bedroom specifically for girls, while the keputran room is for boys. The two rooms are located opposite each other. The keputren room is located next to the pangkeng penganten, while the keputran room is adjacent to the pangkeng keluargo. This layout shows that the rooms of the residents of the house who are married are placed in front of the rooms for the occupants of the house who are not married, especially the nursery for the children. The space organizing is done as a form of parental protection and supervision of children. Their parents can monitor children who leave or enter their room to monitor children who leave or enter their room.

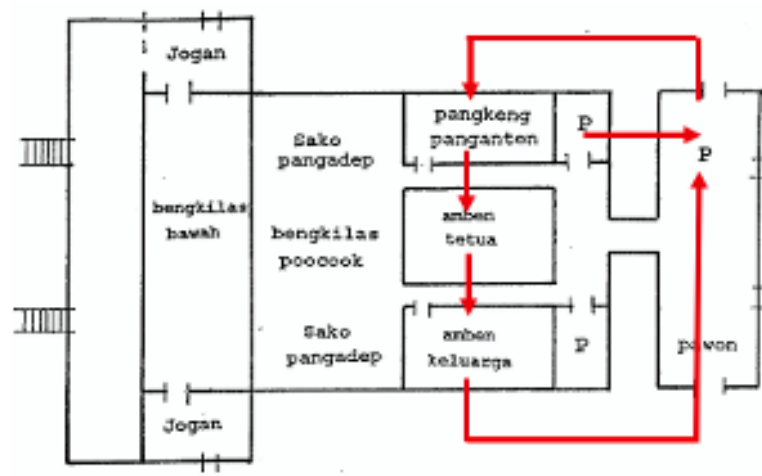

Fig. 6. The room shift cycle follows changes in women's marital status

Unmarried girls are placed in the keputren room, which is located beside the pangkeng penganten. However, when the girl has been proposed or to will marry, the girl is then dipingit by her parents. He was placed in the bedroom in the kitchen until the wedding was held. The couple would change rooms again by occupying the pangkeng keluargo if she was the eldest daughter in the family. This room change will occur if his parents have bequeathed the house. The parents will move to the penunggu jeroo in the pawon.

The newly married couple will live in the house because the custom of settling after the marriage of Palembang people is uxorilocal. This couple will occupy the pangkeng penganten. The couple will then change rooms again by occupying the pangkeng keluargo if the woman's parents have inherited the house or their parents are dead. His parents will move to the penunggu jeroo, which is located in the pawon. If this condition is not possible, then the newly married couple will temporarily remain in the pangkeng penganten until finally the rotation of rooms among the residents of the house is made 
possible by having one of the family members die or establishing a new house not far from their parent's house or being brought by her husband moved away from the house of the woman's parents. The cycle process of moving rooms according to marital status takes place from generation to generation so that the existence of the limas house will always be maintained.

The limas house represents the cultural identity of the Palembang society relates to the societal system based on four social categorization systems. First, the limas house is used for extended families, namely families consisting of the nuclear family and other family members who are cognate relationship in the household economic unit. Second, the spatial arrangement according to gender differences. Three, organizing the layout of the limas house according to kinship relationship status. Four, the layout of the bedrooms is adjusted to the cycle of moving bedrooms based on changes in marital status. The four social categories are the embodiment of the cultural values of the Palembang society so that this vernacular house reflect the cultural identity. Cultural identity as a central mechanism in architectural renewal. Cultural identity is closely related to architectural renewal. Therefore, both serve as effective and valuable tools that can improve the quality of architectural innovation updates (Hosseini \& Shahedi, 2011). The vernacular architecture can be interpreted as a relationship between form, function, meaning within a culture of people living in that area (Ashadi, 2020; Zare \& Kazemian, 2014). Culture is a determining factor in the embodiment of an architectural building, while climate, construction, materials, and technology are only influencing factors (Rapoport, 1980). Vernacular building practices are more sustainable, environmentally friendly, and promote socio-cultural values (Shrestha, 2019).

This cultural identity of Palembang is dynamic. These are influenced by globalization that leads to the unification and standardization of cultures globally. Palembang society is doing social mobilization, both vertically and horizontally. Social interaction with other societies groups is getting more intense and widespread. The local cultural identity, social beliefs and traditional values are influenced by current consumerism trends and homogenization (Asquith \& Vellinga, 2006). Palembang society is doing social mobilization, both vertically and horizontally. These conditions affect Palembang's local cultural values, including change in the societal system, such as family structure, kinship relationship, gender, and the replacement bedroom according to marital status.

Women are wong ruma, which shows the house is identical to women, while men are penegak juray (family enforcers). Women have responsibilities in domestic affairs, including maintaining the house. A married woman with her husband will stay in her parents' limas house. In time, she will become the owner of the limas house until finally, she becomes the penunggu jeroo. Currently, the newly married couple tends to be neolocal. Newly married couples tend not to live in the woman's family home but away from her parents' house. Although some are still uxorilocal but stay in the vicinity of her parent's residence. Women are no longer interpreted as wong ruma but also have a role in the public sector by working. The public sector is a domain for men in Palembang culture. This condition resulted in the limas house being slowly abandoned by the children of the married homeowners. They prefer not to settle in their parent's house so that the family structure changed to a nuclear family, only consisted of parents and unmarried children.

The implication of changing the family structure from extended family to nuclear family is that there is no longer a cycle of changing bedrooms according to changes in marital status. The pangkeng penganten occupied by the newly married couple is not used because it is uxorilocal. Therefore, household members' use of the bedroom tends fixed. For example, a girl will stay in her bedroom until she finally leaves the house for marriage. This change in the family structure resulted in the house's occupants changing one function of the room unused. This change in the function of the house, for example, was experienced by H. Muhammad's limas house in Lorong Tanggo Rajo Village 7 Ulu Palembang. Basically, the layout of this house still follows the general pattern of the layout of the limas house. However, the pangkeng keluargo turned into an open space. Likewise, with the Wak Da Family in Lorong Kenduruan, 7 Ulu Village, Palembang. The function of keputran turns into a warehouse, and the pangkeng keluargo becomes an open space. The owner of the house is pangkeng penganten. Homeowners also change the lower part of the house into rooms for other family members as the number of family members increases (Anwar, 2019).

The difference between men's rooms in the front (public) and women's rooms in the back (private) as an embodiment of women's protection has also changed. The use of space in the limas house is more focused on practical interests so that the use of spacebased on gender differences is less considered, except in ritual ceremonies. Women are no longer the housekeepers who do more activities in the domestic sector but can also play the roles that men have done in the public sector. 


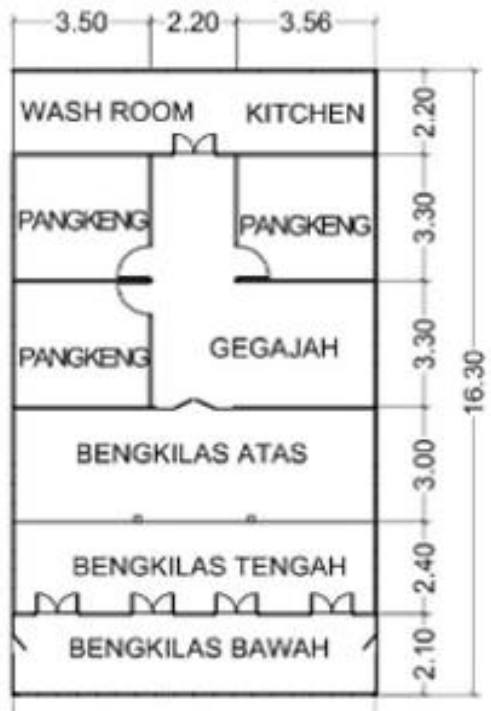

Fig. 7. Layout of Muhammad's limes house (Source: Anwar 2019)

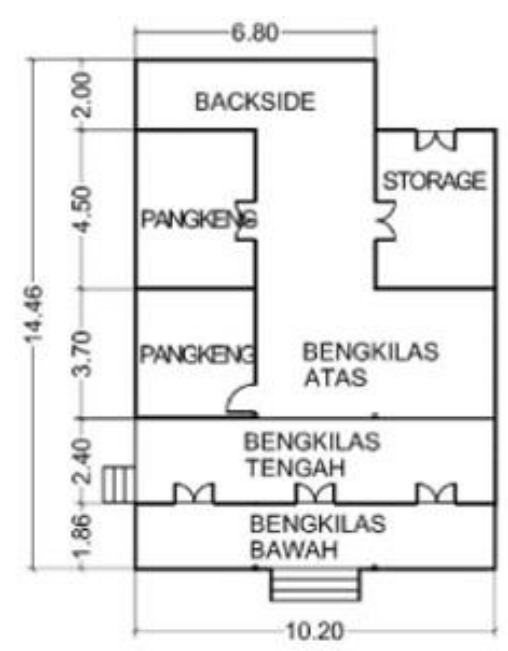

Fig. 8. Layout of Wak Da's limes house (Source: Anwar 2019)

This phenomenon of change describes the function of the limas house due to adaptation to changes in the social system, which has become the new identity of the people of Palembang. Limas house architecture continues to develop as part of the formation of this identity. Limas house as a marker of Palembang's cultural identity is produced, modified, and reproduced so that it has new meanings that can be different from previous meanings. This dynamic continues to process so that changes in the shape and layout of the limas house continue. Nevertheless, these changes still show their function as a residential building. For the Palembang society, the limas house is a place to live; its residents use that to foster family life, both for daily life and traditional ceremonies. Limas house is a place for the internalization, socialization, and enculturation of its inhabitants to occur, which shows intimacy and hierarchy as reflected in horizontal and vertical linearity relationships (J.M.Nas, 1998).

This limas house building changes take place dynamically. The changes in the two case examples that have been raised actually also show that the limas house is no longer meant to live but also as a place of business. The two limas houses turned the room into a place of business. The warehouse room in the $\mathrm{Wa}$ Da's limas house is where the family's business items are stored, while H. Muhammad changed one room into an open space to be used as a clothing store. In other cases, many of the bottom (legs) of the house is walled so that it becomes a closed room and is used as a room or shop, as in the following picture.

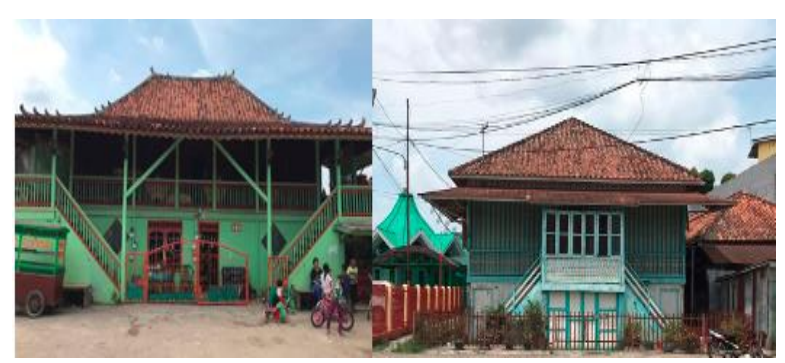

Fig. 9. Changes to the Limas House

Changes in the form and layout of the limas house will continue so that gradually the limas house building with the general pattern of vernacular architecture will disappear. It's just that another "limas house" will appear that has a different form and layout from the previous typical limas house, especially until now there has been no construction of a new limas house. This means that the current limas house will experience changes according to the social dynamics in the community and bring out the architectural characteristics of the limas house with a different form and layout from the previous limas house.

\section{CONCLUSSION}

The vernacular architecture of the limas house acts as a cultural marker that can represent Palembang's cultural identity. This identity represents the societal system, such as family structure, kinship relations, gender, and marital status. This cultural identity is dynamic, which is produced, modified, and reproduced through social processes. The influence of modernization and globalization has affected the societal system, so the form and layout of the house must be adapted to these changes. This change also affects the function of the house, which is no longer just a place to live but also functions as a place of business. 
Palembang's cultural identity is not "as being" but "as becoming". Limas house is modified and reinterpreted as a building capable of accommodating social continuity based on the dynamics of the societal system.

The limas house will still represent the cultural identity of Palembang, and it's just that the embodiment of its form and layout will change following changes in the dynamic cultural identity of the society. The limas house is an arena that shows cultural identity through building changes that are adaptive to ongoing social processes. Limas house will become a symbolic identity that the society interprets differently along with the changing times.

The existence of the limas house is a manifestation of the harmonious human space between the natural environment and the socio-cultural environment. Rumah limas is a cultural landscape that refers to ecological architecture, which considers an ecocentric approach by prioritizing harmony with nature. Therefore, it is necessary to protect, maintain, and develop the limas house by reinterpreting and revitalizing according to the dynamics of the Palembang culture so that the limas house as a cultural identity can be adaptive to the social processes that occur in the community.

\section{ACKNOWLEDGMENT}

This article is part of the research results funded by Sriwijaya University through the Hibah Unggulan Kompetitif 2020. I want to thank the Rector and Chair of the Sriwijaya University Research and Community Service Institute for facilitating this research. I also thank the research team and field assistants who have worked hard to collect data in the field. Finally, thanks are also addressed to the informants and related parties who cannot be mentioned one by one.

\section{REFERENCES}

Anwar, W. F. F. (2019). The Building Performance of Limas House; Dealing with Current Context. Journal of Physics: Conference Series, 1198(8). https://doi.org/10.1088/1742-6596/1198/8/ 082029

Ashadi, A., \& Jakarta, U. M. (2020). Positioning architecture in culture. 47(1), 27-33. https://doi.org/10.9744/dimensi.47.1.27-34

Askarizad, R. (2018). Influence of Socio-Cultural Factors on the Formation of Architectural Spaces (Case Study: Historical Residential Houses in Iran). Creative City Design, 1(1), 29 36. http://crcd.sinaweb.net/article_664200.html
Asquith, L., \& Vellinga, M. (2006). Vernacular Architecture in the 21st Century. Vernacular Architecture in the 21st Century. https://doi.org/ 10.4324/9780203003862

Aziz, I., Siswanto, A., Sueca, N. P., \& Purnama, D. H. (2019). The tradional architecture of palembang limas house evaluation of physical proportion of Palembang limas house with three Bengkilas in Seberang Ulu Palembang. International Journal of Engineering and Advanced Technology, 9(1), 3631-3635. https://doi.org/10.35940/ijeat.A2702. 109119

Bambang, W., Ari, S., Susilo, K., \& Widya Fransiska Febriati, A. (2016). Cultural Approach of Sustainability in Dwellings Culture Riparian Community Musi River Palembang. DIMENSI (Journal of Architecture and Built Environment), 43(2), 85-92. https://doi.org/10.9744/dimensi.43.2.85-92

Bedelean, B. (2012). Pro ligno. 8, 89-99.

Bourdieu, P. (1977). The Berber House, in Mary Douglas (ed.), Rules and Meanings, 98 - 110. Harmondsworth, Penguin.

Budiyuwono, H. (2016). Science and Engineering Applications Relation form and function of limas house in the city of Palembang. Science and Engineering Applications, 1(2), 3-7.

Cunningham, C. (1964). Order in the Atoni house. Bijdragen Tot de Taal-, Land-En Volkenkunde, 120(1ste Afl), 34-68.

Ellen, R. (1986). Microcosm, Macrocosm and The Nuaulu House: Concerning the Reductionist Fallacy as Applied to Metaphorical Levels.

Gulati, R., Sehgal, V., Qamruddin, J., \& S., R. A. (2019). Architectural Spaces as Socio-Cultural Connectors: Lessons from the Vernacular Houses of Lucknow, India. Journal of the International Society for the Study of Vernacular Settlements, 6(4), 30-48.

Hosseini, E., \& Shahedi, B. (2011). Paper submitted to the 2 nd International Conference on Architecture \& Structure Augmentation of Cultural Identity and Architectural Innovation. May.

J.M.Nas, P. (1998). The house in Indonesia Between globalization and localization. Bijdragen Tot de Taal-, Land-En Volkenkunde, 2, 335-360.

$\mathrm{Ng}, \mathrm{C}$. (2006). Raising the House Post and Feeding the Husband-Givers: The spatial categories of social reproduction among the Minangkabau. Inside Austronesian Houses: Perspectives on Domestic Designs for Living, 1974, 1982. https://doi.org/10.22459/ia.09.2006.05

Sheida Ettehad, Amir Reza Karimi Azeri, G. K. (2014). The role of culture in promoting architectural identity. European Online Journal 
of Natural and Social Sciences, 3(4), 410-418. http://www.european-science.com

Shrestha, E. (2019). Running Head: Vernacular Architecture In Contemporary Context In The Outskirts of Kathmandu Valley 1, 1-18. https://www.academia.edu/38247325/vernacular _architecture_in_contemporary_context_in_the_ outskirts_of_kathmandu_pdf

Siswanto, A., Salim Binti Syed Salim, A., Dalilah Dahlan, N., \& Hariza, A. (2011). Architectural and Physical Characteristic of Indigenous Limas Houses in South Sumatra. Local Wisdom in
Global Era. Enhancing the Locality in Architecture, Housing and Urban Environment. A. Indigeneous Architecture as a Basic Architectural Design, 1, 56-63.

Taal, S. (2008). The limas house of Palembang. In Indonesian Houses. 2, 363-389. https://doi. org/10.1163/9789004253988_013

Zare, M. H., \& Kazemian, F. (2014). Reviewing the Role of Culture on Formation of Vernacular Architecture. European Online Journal of Natural and Social Sciences Special Issue on Architecture, 3(4), 547-553. 